\title{
U bow activator, an alternative functional orthodontic appliance
}

\author{
Anita Budihardja* and Jusuf Sjamsuddin** \\ * Orthodontics Adaptation Program at the Department of Orthodontic \\ *** Department of Orthodontic \\ Faculty of Dentistry, Airlangga University \\ Surabaya - Indonesia
}

\begin{abstract}
Functional orthodontic treatment has been proved to be one of the most effective and successful treatment modality in orthodontics. Functional orthodontic appliance can only be applied in growing young patients. Since Andresen's activator, there are a lot of other functional appliances that have been developed and introduced. U bow activator, introduced by Prof. Karwetzky from Wilhelms University of Muenster, is one of the appliances that can be chosen. In this case report, $U$ bow activator type 1 is used to treat class II malocclusion and proved to give satisfying result. Patient's cooperation is the most important factors in achieving success.
\end{abstract}

Key words: Functional orthodontic appliance, U bow activator, Karwetzky

Correspondence: Anita Budihardja, c/o: Bagian Ortodonsia, Fakultas Kedokteran Gigi Universitas Airlangga. Jln. Mayjend. Prof. Dr. Moestopo 47 Surabaya 60132, Indonesia.

\section{INTRODUCTION}

Daskalogiannakis ${ }^{1}$ in Glossary of Orthodontics Terms defines functional appliance as a removable or fixed appliance that alters the posture of the mandible. This appliance transmits the forces created by the resulting stretch of the muscles and soft tissues and by the chance of the neuromuscular environment to the dental and skeletal tissues to produce movement of teeth and modification of growth. In 1880, Kingsley introduced the term and concept of "jumping the bite" for patients with mandible retrusion. He inserted a vulcanite palatal plate consisting of an anterior incline that guided the mandible to a forward position when the patient close it. ${ }^{2}$

Later in 1902, Pierre Robin published an article describing an appliance, called the monobloc, because it was a single block of vulcanite. He used this appliance to position the mandible forward in patients with glossoptosis and severe mandible retrognathism who risked occluding their airways with their tongues. This problem usually associated with cleft palate and known as Pierre Robin syndrome. Robin noted that forward mandible posture reduced this hazard and also led to significant improvement in the jaw relationship. ${ }^{2,3}$

Inspired by Kingsley appliance, without first knowing Robin's Monobloc, Andresen developed a mobile, loose fitting appliance modification that transferred functioning muscle stimuli to the jaws, teeth and supporting tissues. At first, Andresen used his appliance as a retainer over a summer vacation for his own daughter after removal of fixed appliances used to correct a distocclusion. This appliance was a modification from Kingsley appliance, to which he added lateral extensions to cover the lingual aspects of the mandibular teeth. The "biomechanical working retainer" was also preventing mouth breathing. Further use of the "retention activator", as he later called the device, brought encouraging result. He found the results of the previous treatment were not only preserved but in many cases actually improved during the vacation period. ${ }^{2,3}$

Later, Andresen worked together with Häupl, developing the concept of the appliance, which they both called activator. They believed that it has ability to activate the muscle force. They regarded "functional jaw orthopedics" as vastly superior to all previous methods in bringing about growth changes in an entirely physiological manner. They believed that this appliance induced growth changes in physiological manner and stimulated or transformed the natural forces with an intermittent functional action transmitted to the jaw, teeth and investing tissue. ${ }^{2,3}$

The introduction of Andresen's activator was a milestone in the history of orthodontics. Since then the development of removable appliances and modification of activator grew so fast, especially in Europe. In 1964, Rudolf Karwetzky from Wilhelms University Münster, with his article "Ein neues Funktions-kieferorthopädisches Gerät" at the Deutsche Zahnärzteblatzt, introduced a new functional appliance, which he called $\mathrm{U}$ bow activator or U Bügel Activator (UBA).

U bow activator from Karwetzky (Figure 1) consists of maxillary and mandibular active plate, joined by a $U$ bow in the region of the first permanent molars. In addition to acrylic covering the lingual tissue aspects, gingiva and the teeth, the plates also extend over the occlusal aspects of all teeth. Each plate has labial bow and protrusion bow (closed spring), and the upper plate has expansion screw. ${ }^{4}$ Labial bow, made from $0.9 \mathrm{~mm}$ stainless steel wire, extends from 
canine to canine. Protrusion bow extends from middle of canine to canine at the palatal region, made from $0.7 \mathrm{~mm}$ stainless steel wire. The height of these two components depends on front teeth movements that want to be achieved. Expansion screw is placed in the upper plate, at the height of P1 or dm1. U Bow made from $1.2 \mathrm{~mm}$ wire, placed at both sides at the height of M1. U bow activation will define the mandible reposition. ${ }^{4}$

There are three types of $U$ bow activator developed by Karwetzky: a) UBA type 1. In type 1, the U bows are placed downward and this activator is used to correct class II malocclusion; b) UBA type 2. In type 2, the U bows are placed upward and this activator is used to correct class III malocclusion; c) UBA type $3 \mathrm{a}$ and $3 \mathrm{~b}$. The placements of the $\mathrm{U}$ bows are different between the right side and the left side. This type is usually used to correct asymmetry and functional midline shifting (Figure 2).

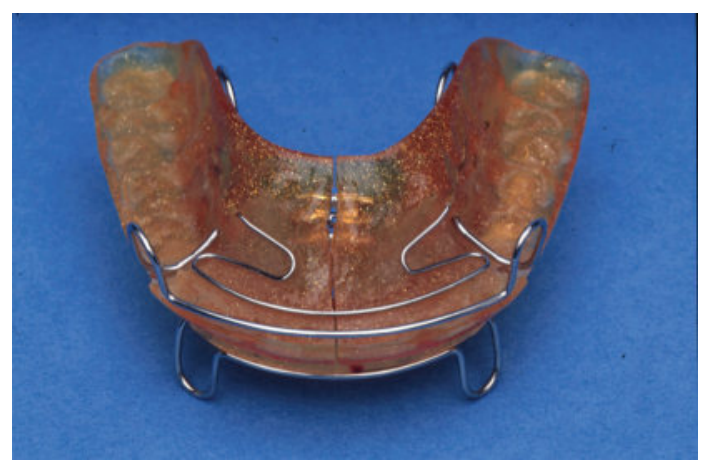

Figure 1. U bow activator from Karwetzky.
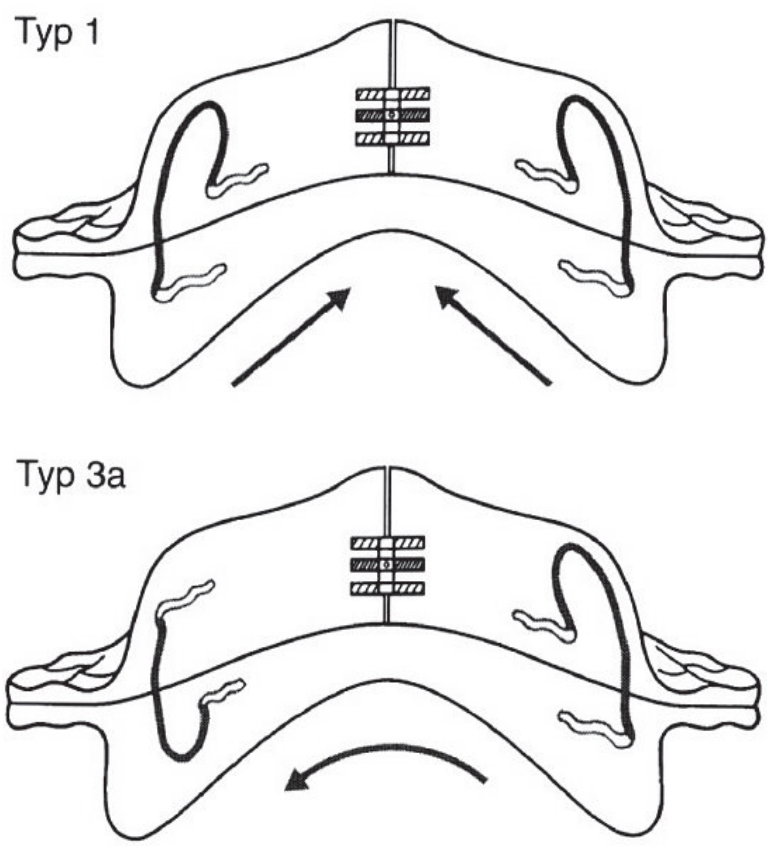

Figure 2. Three types of UBA developed by Karwetzky.
From these three types of UBA, the one that used most is UBA type 1 to correct class II malocclusion. Ehmer, with the dysgnathy classification, said that indication of using UBA type 1 are mandible retrognathy, maxilla prognathy, upper front teeth protrusion and or lower front teeth retrusion, deck bite (Angle class II div 2), and skeletal or functional asymmetry that accompany class II malocclusion. ${ }^{4,5}$

Just as other functional appliance, the optimal time of using UBA are during growth, between 8-11 years old. UBA can also be used earlier (4-7 years), usually in patients with class II div 1 malocclusion accompanied by extreme over jet. This kind of malocclusion can enhance the risk of front teeth trauma, caused negative functional pattern (lower lip is trapped behind upper front teeth and incompetence lip closure) and usually caused psychological stress to the patient (being mocked about appearance). ${ }^{4,5}$
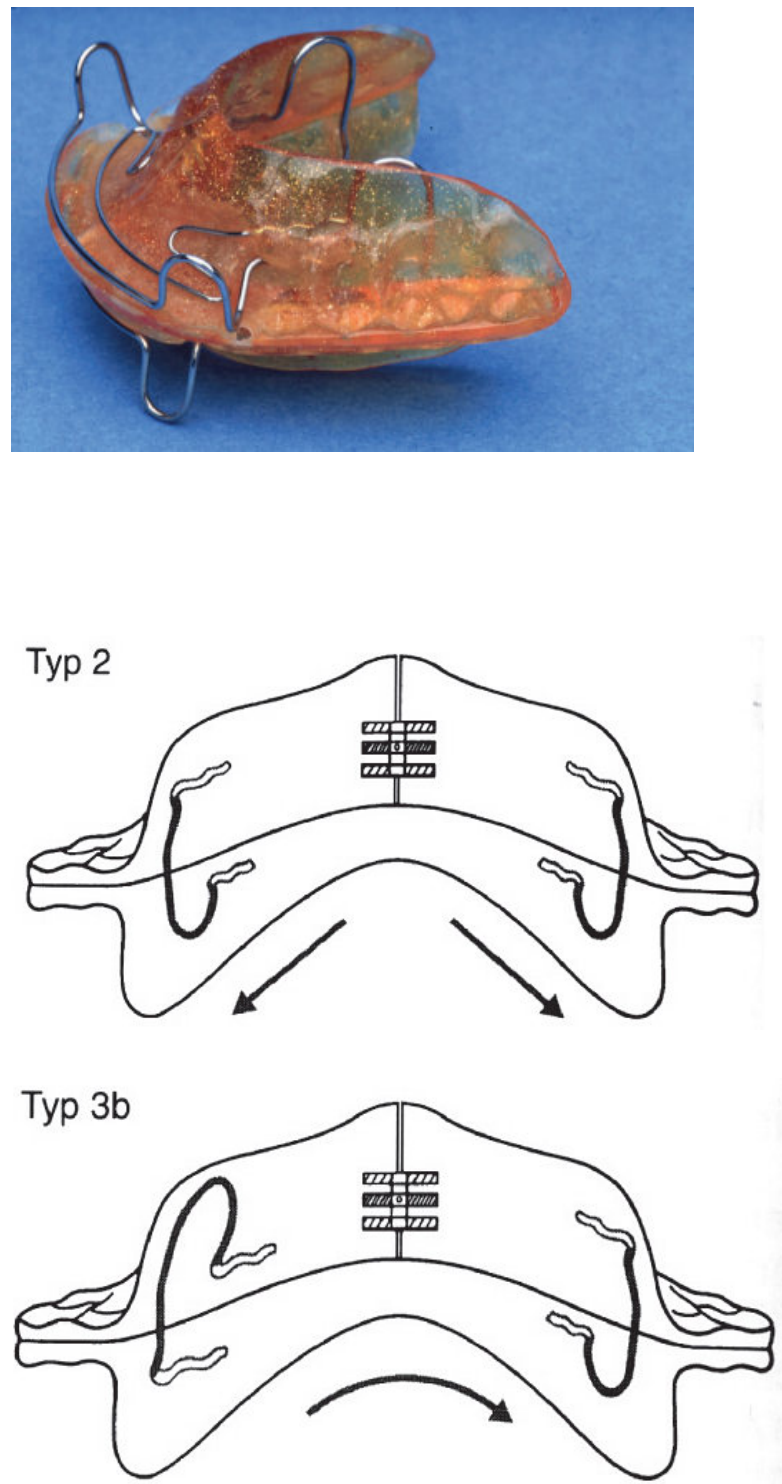
Modes of actions of UBA are splinting of dental elements, sequential anterior reposition of the mandible (stepwise forward positioning of the mandible), selective transversal expansion of the maxilla and incorporation of active elements for desired tooth movement. Acrylic relief on occlusal and palatal (lingual) region will give splinting effect to the teeth. Acrylic is usually grinded when permanent teeth are erupting, or when elongation of posterior teeth is wanted. ${ }^{4-6}$

$\mathrm{U}$ bow that join the upper and lower plates can be activated (Figure 3 ) and this activation will caused sequential anterior reposition of the mandible. The construction bite is made 3-4 mm sagittally to anterior. After using the UBA for 3-5 months, activation can be started. The activation is usually $2 \mathrm{~mm}$ every $2-3$ months. ${ }^{4-6}$

In class II div 1 malocclusions with mandible retrognathy, the upper jaw is usually transversal underdeveloped. By using UBA, it will be possible to do anterior reposition of the mandible together with transversal maxillary expansion. This expansion can be started after 2 months using the UBA (adaptation time) and can be done 1-2 times a week. ${ }^{4-6}$

Tooth movement, even limited, can also be achieved with labial bow and protrusion bow at upper and lower jaw. Torque control at upper front teeth (not active torque movement) can be achieved if labial bow placed passive more gingivally and the protrusion bow active and more incisal. Inclination and position of lower front teeth can also be corrected by using labial bow and protrusions bow correctly. $^{4-6}$

\section{CASE}

Nine years old male patient came to Department of Orthodontics at Wilhelms University Muenster with chief complaint that his upper front teeth was too protruded. He has difficulties to close his mouth and his upper fronts teeth were exposed at relax position. His self confidence was low because he was often mocked by his brothers and friends as bugs bunny. Anamnesis showed that some people at his family (his elder and younger brother) have the same problem (protruding upper teeth/jaw). He also has incompetence lip closure and he breath oft through the mouth. Extra oral photos before and after treatment can be seen in Figure 4 and 5.

Molar and canine relations on both sides were class two. He has deep curve of spee, spacing on upper jaw, overjet is $11 \mathrm{~mm}$ and overbite is $6,5 \mathrm{~mm}$. Panoramic radiograph showed that all permanent teeth exist, except M3 that can not yet be seen at this age (Figure 6).

Cephalometry analysis shows class II malocclusion with normal maxilla and mandible retrognathy, the face was mesofacial with normal growth pattern, upper and lower front teeth were proclined and the profile was convex (Figure 7).

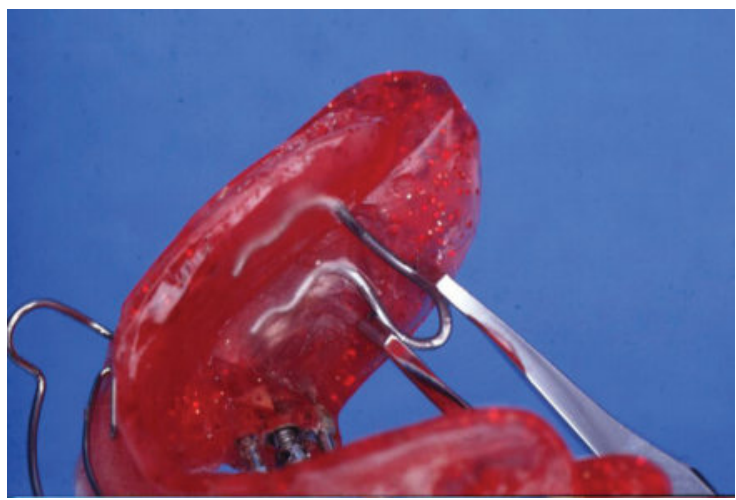

Figure 3. U bow activation by making the "U" smaller.
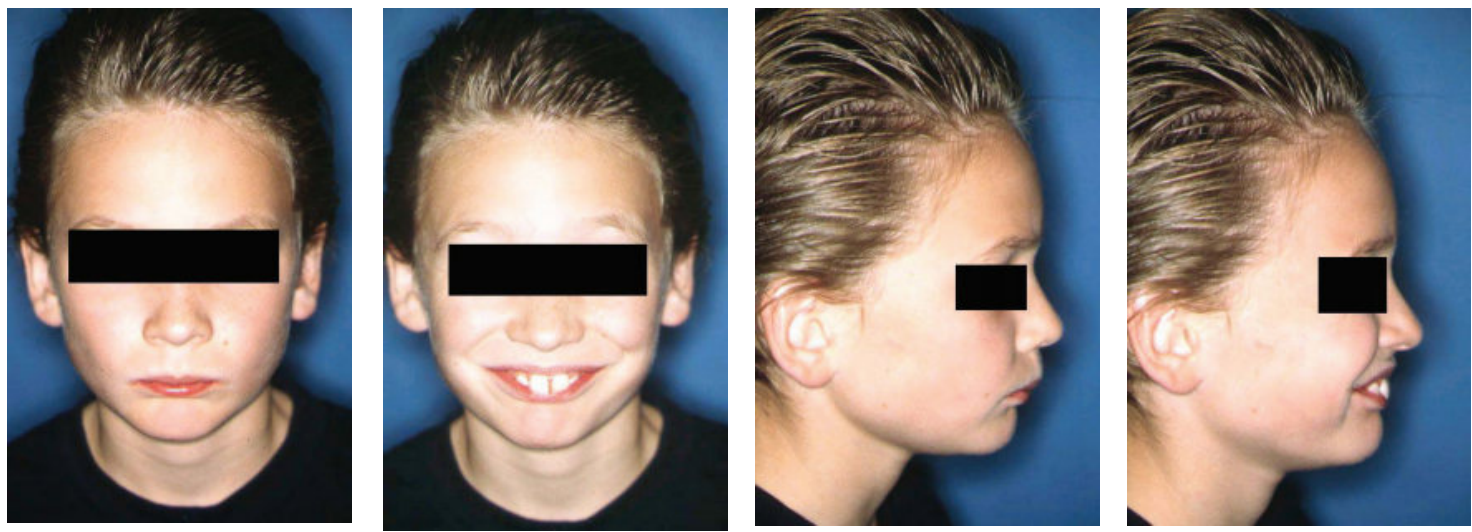

Figure 4. Extra oral photos before treatment. 

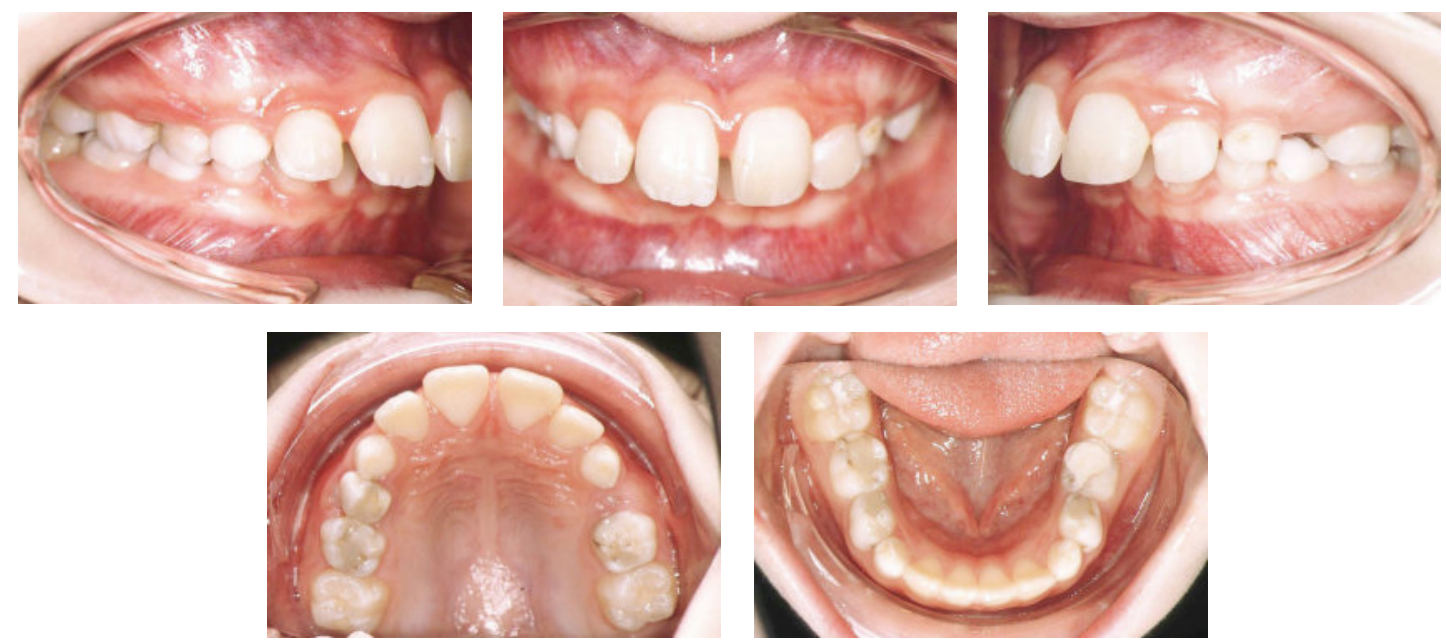

Figure 5. Intra oral photos before treatment.

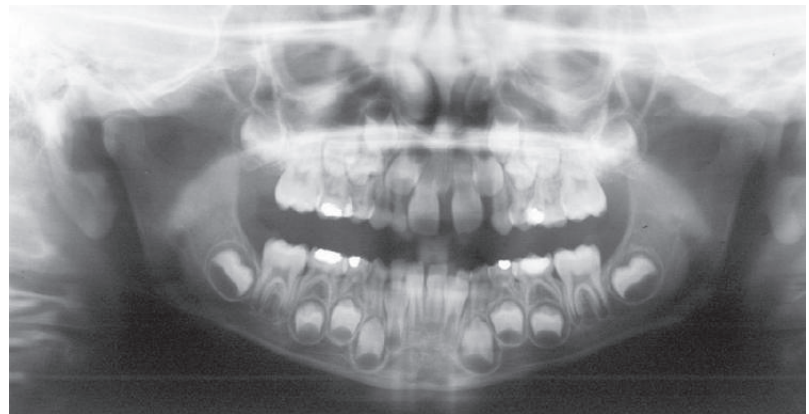

Figure 6. Panoramic radiograph before treatment.

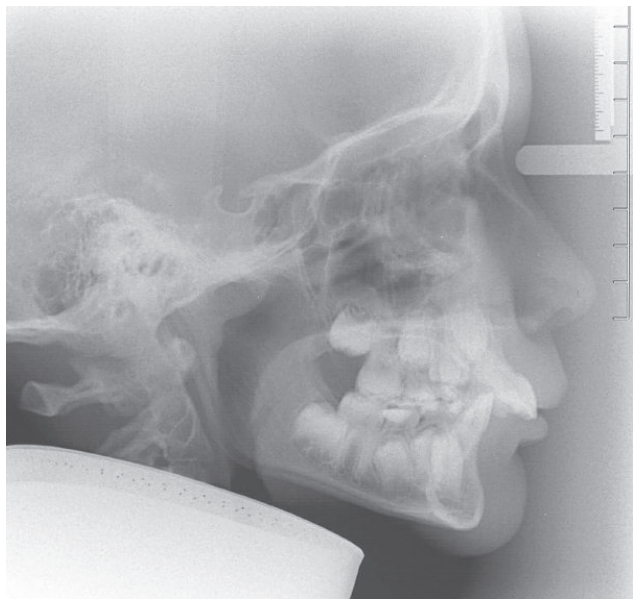

Figure 7. Cephalometry radiograph before treatment.
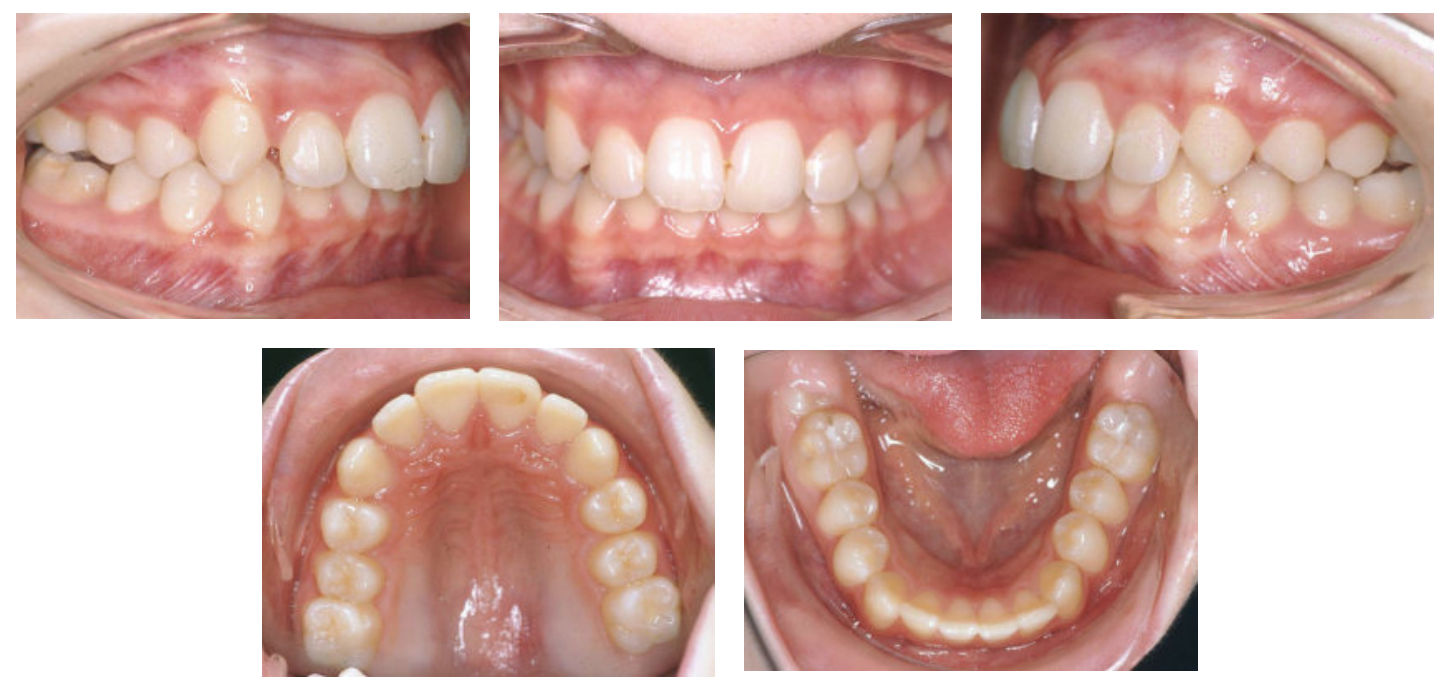

Figure 8. Intra oral photos after 15 months using UBA. 


\section{CASE MANAGEMENT}

Our treatment plan was using functional appliance to achieve anterior reposition of the mandible and to influence the growth of the mandible to reach its maximum. Functional appliance used was U Bow Activator type 1 from Karwetzky. The first construction bite made was $4 \mathrm{~mm}$ sagittal to anterior, vertical $4 \mathrm{~mm}$ and transversally lower midline was adjusted to midline of the face. Transversal expansion in upper jaw was also needed in this case.

During the first six months, patient's cooperation was not so good. He lost his UBA once that a new one has to be made. After that incident, patient was motivated during his visits to the clinic, and since that his motivation became better. He wore his UBA regularly, all night and during day time as well. The UBA was activated $2 \mathrm{~mm}$ every 2-3 months and the expansion screw once in a week. After 15 months using UBA (Figure 8), his over jet was reduced to $7 \mathrm{~mm}$ and he had no difficulties wearing the UBA at all.

After using UBA for 25 months (Figure 9 and 10), over jet was reduced to $2-3 \mathrm{~mm}$ and the profile changed significantly. Molar relationships on both sides were class 1. Both patient and parents were happy and satisfied with the treatment result and they did not want any further orthodontic treatment with fixed appliance. It was decided to go to retention phase and during this stage the patient is told to wear UBA only at nights.

After 15 months using UBA as retainer (Figure 11 and $12)$, the treatment result was stabile. Patient has stabile static and dynamic occlusion, nice profile, beautiful smile and his self confidence become better after orthodontic treatment. Patient and his parents were highly satisfied with treatment result.
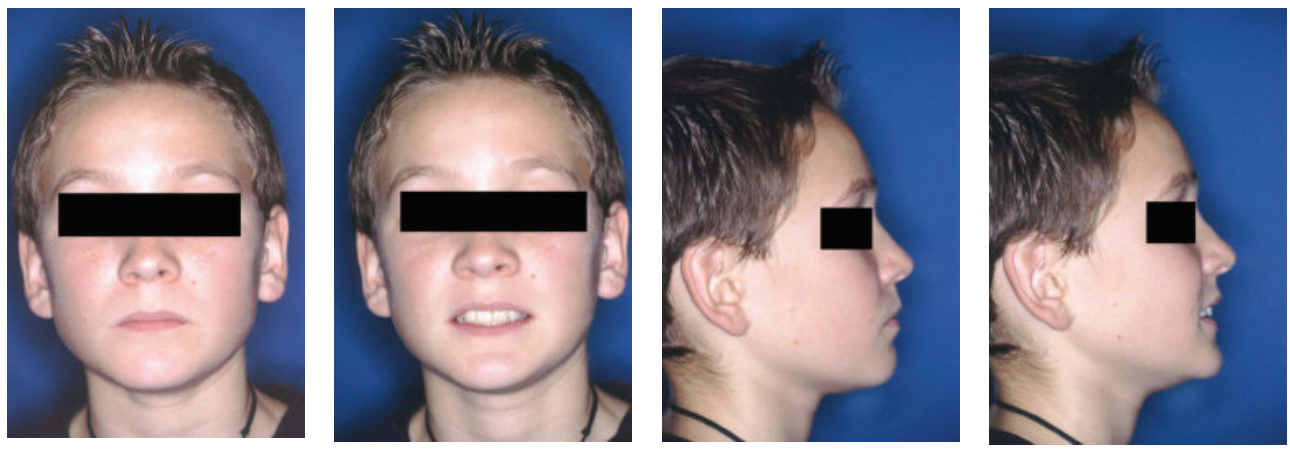

Figure 9. Extra oral photos after 25 months using UBA.
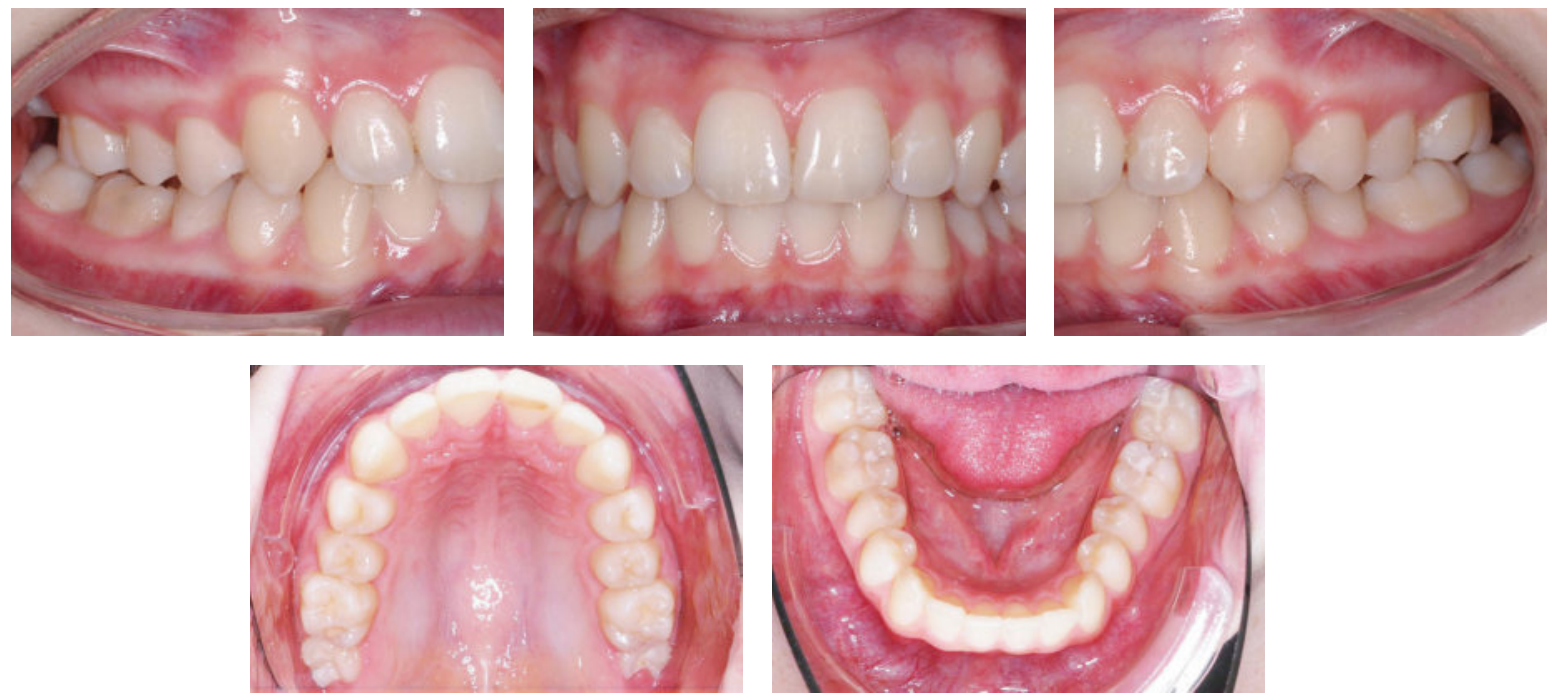

Figure 10. Intra oral photos after 25 months using UBA. 

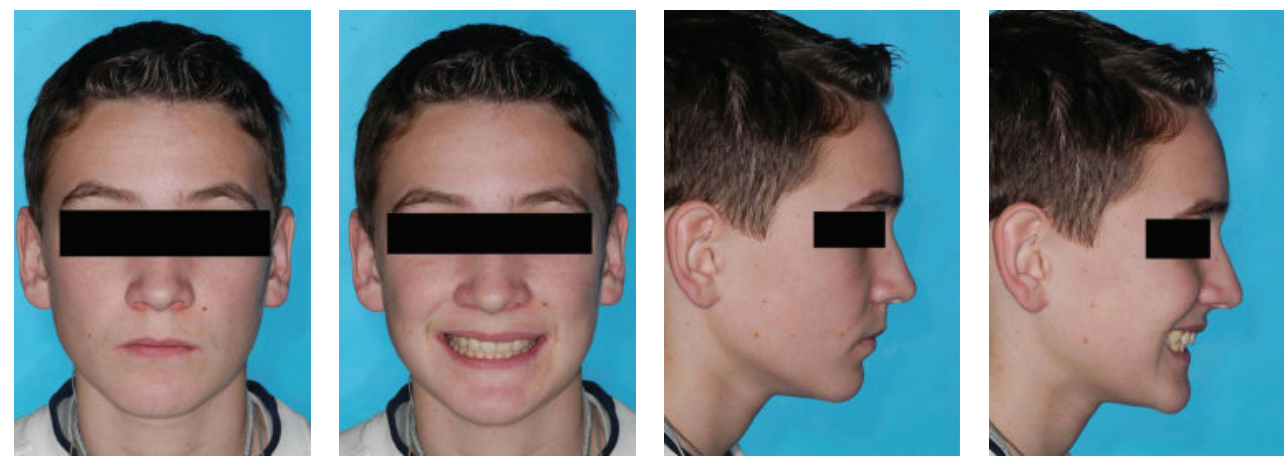

Figure 11. Extra oral photos after 15 months using UBA as retainer.
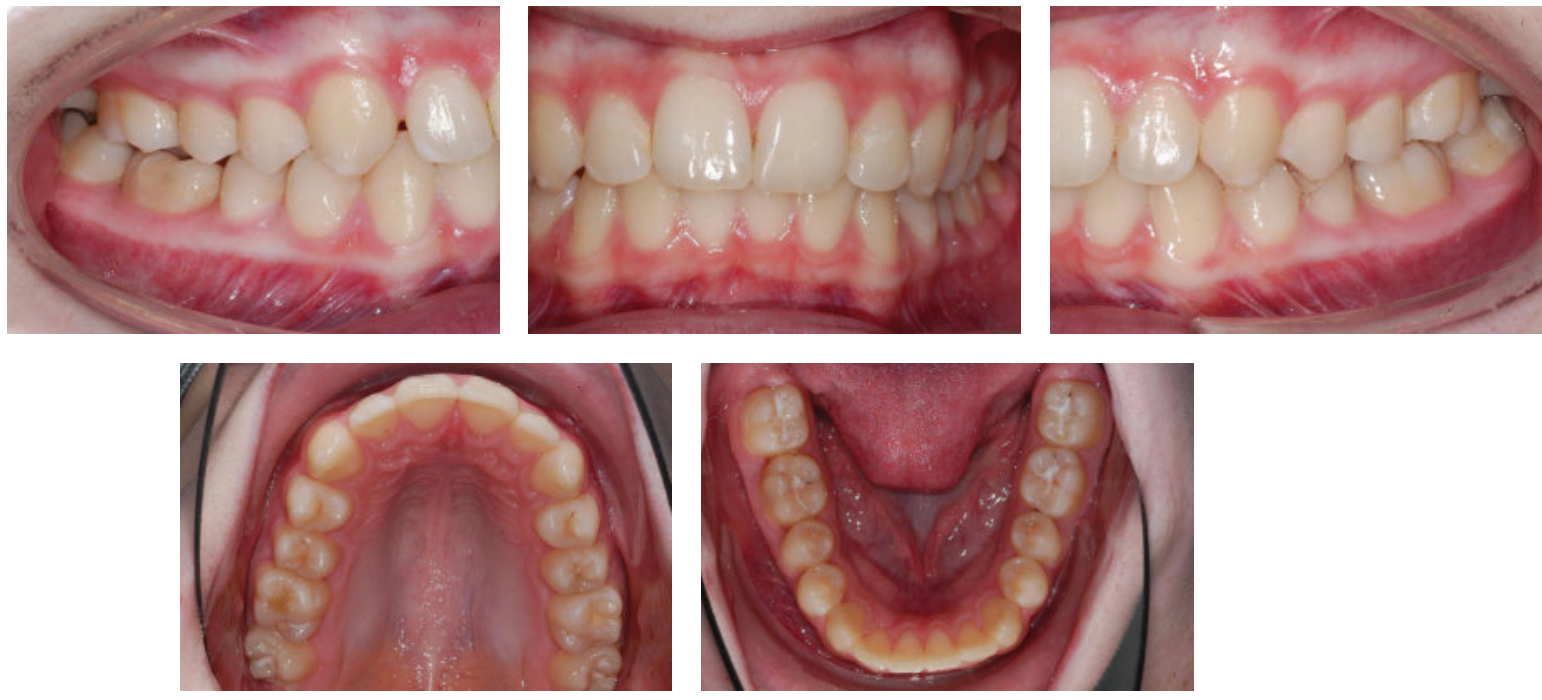

Figure 12. Extra oral photos after 15 months using UBA as retainer.

\section{DISCUSSION}

$\mathrm{U}$ Bow Activator is one of functional appliance that can be use to place mandible forward and to modify the growth in class II malocclusion. Benefit of using UBA is that the operator can do forward positioning of the mandible gradually. Karwetzky, in 1964, postulated that gradually forward positioning of the mandible is more effective than a direct anterior reposition. ${ }^{3-5}$ His postulation is then proved with the experiment done by Petrovic in 1975. The experiment did by Petrovic et.al on rats showed that gradual mandible reposition will give result that is more stable and can enhance the growth in condyle effectively. ${ }^{4,7}$

Gradual forward mandible positioning was done in this patient. At the beginning of the treatment, construction bite was made only $4 \mathrm{~mm}$ to anterior (patient's over jet was $12 \mathrm{~mm}$ ) and after 6 months $\mathrm{U}$ bow was activated $1-2 \mathrm{~mm}$ every 2 months. After 25 months using UBA, the over jet was reduced to $2-3 \mathrm{~mm}$. The maxilla was transversally expanded by opening the expansion screw once in a week.

Skeletal changes that can be achieved with UBA are growth restriction of the maxilla (when combined with head gear), unwanted reaction of the maxilla can be minimized (such as anterior-inferior rotation of the maxilla), enhance the growth in condyle area so that optimal growth border for each individual can be reached, and enhance the growth in temporal and dentoalveolar region which can stabilize treatment result. ${ }^{4,5}$

UBA can also cause dental changes which are torque control in anterior front teeth (by placing labial bow and protrusion bow correctly) and avoiding unwanted dental changes such as proclination of lower front teeth. Beside skeletal and dental changes, UBA can also cause neuromuscular adaptation which is need for stabilization of treatment result. ${ }^{4,6}$

Significant changes was seen in this patient, class I relation in molar and canine region was achieved, with overbite and over jet 2-3 mm. Upper and lower front teeth inclination were in normal and treatment result in stabile even until 15 months after retention time.

Optimal result can be achieved with correct diagnosis and treatment plan, at the right time regarding the age of the patient. Ehmer ${ }^{5}$ said that the optimal time to start treatment with functional appliance is before patient reached the peak of the growth (stadium MP3 = in carpal radiograph). After 
that, functional appliance can still be used even though the treatment started at the late stage. ${ }^{5}$

When the patient is still in stadium MP3 = according to the carpal radiograph (epiphyse and diaphyse are the same width, usually 9,7 years old in girls and 11,2 years old in boys), it is optimal to start orthodontic treatment with functional appliance. When the patient is in stadium MP3 cap (epiphyse is capping the diaphyse, usually 12,4 years old in girls and 14,0 years old in boys), treatment success is limited and will not be as optimal when it is started before. Beginning of the treatment time is considered late, and can only be successful with good patient cooperation and favorable growth pattern. ${ }^{5}$

Being in MP3 unit stadium (epiphyse and diaphyse are joined, usually 14,3 years old in girls and 16,0 years old in boys), the patient is considered too old for orthodontic treatment with functional appliance. Treatment can still be done with the knowledge that success rate is not high and must be support with patients cooperation and favorable growth pattern as well. ${ }^{5}$

Patient's cooperation, as said before, is a very important factor in determining treatment success and stability. ${ }^{5}$ During the first 6 months, patients cooperation was bad, he did not wear his appliance as told and he even lost his UBA. A new UBA was made and the patient was motivated. After his cooperation was better, he wore his appliance all night and for several hours during the days as told, he came to the clinic for control regularly and always had good oral hygiene. These points really contribute a lot in achieving good treatment results.

It concluded that $\mathrm{U}$ bow activator from Karwetzky is one of functional appliance that can be used in treating class II malocclusion, both skeletal or dentoalveolar. The indications and contra indications for the use of an U-bow activator have to be considered within the context of the indications dentofacial orthopedics and functional orthodontics. There is a broad area of clinical application during the period fo growth for different forms of class II malocclusion. There are some effects that can be achieved by using U-bow activator: splinting of the teeth, stepwise forward positioning of the mandible, selective maxillary expansion, and incorporation of active elements for desired tooth movement. This appliance is proved to work well and is easy to be used or made.

\section{REFERENCES}

1. Daskalogiannakis J. Glossary of orthodontic terms. $1^{\text {st }}$ ed. Berlin: Quintessence Publishing; 2000. p. 18, 123.

2. Graber TM, Neumann B. Removable orthodontic appliance. $2^{\text {nd }}$ ed. Philladelphia: WB. Saunders Co; 1984. p. 175-243.

3. Graber TM, Rakosi T, Petrovic AG. Dentofacial orthopedics with functional appliance. $2^{\text {nd }}$ ed. St Louis: Mosby; 1997. p. 161-222

4. Ehmer U. U Bügel aktivator. In: Miethke RR, Drescher D, editors. Kleines Lehrbuch der Angle Kalsse II,1 unter besondere Berücksichtigung der Behandlung. Berlin: Quintessence Bibliothek; 1996. p. 161-82.

5. Ehmer U. Indikatiobshinweise für den U Bügel Aktivator Typ 1 nach Karwetzky. Prakt Kieferorthop 1988; (2):75-84

6. Ehmer U. Indikatiobshinweise für den U Bügel Aktivator Typ 1 nach Karwetzky, Wirkungsprinzipien - Indikationsbereiche - Klinische Handabung. Prakt Kieferorthop 1994; (8):11-22.

7. Petrovic A, Gasson N, Oudet C. Wirkung der übertriebenen posturalen Vorschubsteilung des Unterkiefers auf das Kondylenwachstum der normalen und der mit Wachstumhormonen behandelten Ratte. Fortsch Kierorthop 1975; (36):86-97. 